\title{
Solar Based Air Compressor for Inflating Tyres
}

\author{
Mrs. O. Hema Latha ${ }^{1}$, Mr. S.Irfan Sadaq ${ }^{2}$, Mr. Md. Abdul Raheem Junaidi ${ }^{3}$ \\ ${ }_{1,2,3}$ (Mechanical Engineering Department, Muffakham jah College of Engineering and Technology, \\ Hyderabad, Telangana, India)
}

\begin{abstract}
Solar energy is renewable source of energy which can be used for many applications like power generation, water heating \& cooking etc. The hard part is capturing the sunlight. It shines all over the earth. Air compressors, sometimes referred to as gas compressors, are devices or tools that reduce the volume of a gas thus creating pressure and heat in the gas being compressed. The most common application of this technology is the common or garden air compressor that you might have at home for inflating tyres or using with a spray painting tool. The basic set up of a solar power air compressor is a number of solar panels that are made up of photovoltaic cells. The cells create direct current electricity through the reaction of photons with silicon dioxide. This direct current is used to power a motor that works the compressor unit. In the present work solar photo voltaic is used to generate the power to run the air compressor used for inflating tyres.
\end{abstract}

Keywords: solar energy, compressor, volume, solar photovoltaic, electricity.

\section{Introduction}

An Air Compressor is a device that converts power (usually from an electric motor, a diesel engine or a gasoline engine) into kinetic energy by compressing and pressurizing air, which, on command, can be released in quick bursts. There are numerous methods of air compression, divided into either positive-displacement or negative-displacement types. Positive-displacement air compressors work by forcing air into a chamber whose volume is reduced to compress the air. Piston-type air compressors use this principle by pumping air into an air chamber through the use of the constant motion of pistons[11]. They use one-way valves to guide air into a chamber, where the air is compressed. Rotary screw compressors also use positive-displacement compression by matching two helical screws that, when turned, guide air into a chamber, whose volume is reduced as the screws turn. Vane compressors use a slotted rotor with varied blade placement to guide air into a chamber and compress the volume[2]. Negative-displacement air compressors include centrifugal compressors. These use centrifugal force generated by a spinning impeller to accelerate and then decelerate captured air, which pressurizes it.

Conventional air compressors are used in several applications:

- To supply high-pressure clean air to fill gas cylinders

- To supply moderate-pressure clean air to a submerged surface supplied diver

- To supply moderate-pressure clean air for driving some office and school building pneumatic HVAC control system valves

- To supply a large amount of moderate-pressure air to power pneumatic tools

- For filling tyres

- To produce large volumes of moderate-pressure air for large-scale industrial processes (such as oxidation for petroleum coking or cement plant bag house purge systems).

Most air compressors either are reciprocating piston type, rotary vane or rotary screw. Centrifugal compressors are common in very large applications. There are two main types of air compressor's pumps: oil lubed and oil-less. The oil-less system has more technical development, but they are more expensive, louder and last for less time than the oiled lube pumps, but the air they deliver is of better quality.

\section{Solar Air Compressor}

A solar powered air compressor does exactly the same as a regular compressor, but it's powered by the sun. Air compressors are often used to power drills used by oil and gas companies because there is no power available, solar powered air compressors make powering these drills very easy[4]. It may seem strange to use solar powered drills in order to find fossil fuels, but it really is done! It may only be a tiny thing but it does make a difference. We can only run solar powered air compressors from the solar panels, you cannot run one from a battery at night for example as this could cause damage to the delicate circuit. The solar powered air compressor is completely green and will look after the environment. Solar technology is now small enough to be used to charge your cell phone, run a laptop[8]. You can also buy smaller solar air compressors to run smaller drills and machinery. The solar power air compressor is basically a standard air compressor with the power being generated from the sun. If you buy one of these compressors you should have everything you need. Here we have designed a Solar based Air Compressor by using AT89S52 controller[1]. 
Specificationsof Solar Panel and Air Compressor

\begin{tabular}{|c|c|c|}
\hline S.No & Description & Specification \\
\hline 1 & Product Type & 100Watt Photovoltaic Solar Panel \\
\hline 2 & Rated Output Voltage & 12 Volts \\
\hline 3 & Solar Cell Grade (A, B, C) & Prade A \\
\hline 4 & Cell Type & 25 years \\
\hline 5 & Life Time & 100 Watts \\
\hline 6 & Output (Watts) & MC IV (MC4) Cables attached to junction box \\
\hline 7 & Connector Type & \\
\hline
\end{tabular}

Solar Panel will produce an average of 300 Watt Hours (Wh) or 25Amp Hours (Ah) of charge per day. Which is 5 hours of Sun Shine.

Air Compressor Specifications:-

- High Power Model of 12V Car Electric Air

- Compressor Tyre Pump - Tyre Inflator

- High Power Model 250 PSI has a Extra High Power Motor for Better

- Inflation power Stronger Outer Body

- Long air Pipe

- Simply use this for fast \& easy inflation of car tyres"

- No strength required for pumping air as it is all electronic \& is powered directly from your car battery

- Perfect for anyone who wants a ease while inflating a tyre

- Time saving as compared to mechanical pump

- Quick operation

- Very Compact and easy to store in car dickey

- Robust and Durable Design

- Easy to use - just plug into your car cigarette lighter for power, slip

- universal adapter over tyre valve and you are ready to inflate

- An invaluable kit for the motorist, no need to be stranded if you have a puncture, simply plug into your car cigarette lighter \& place the nozzle over the tyre valve

- This inflator has a pressure gauge that reads in $\mathrm{lb} / \mathrm{in}$ and $\mathrm{kg} / \mathrm{cm}$ bar

- Compact inflator, plugs into car cigarette lighter for the easy inflation of car or bicycle tyres, sports balls.

\section{Calculations For Solar Panel Charging:-}

Assuming that there are no losses in the charging process and that the sun continues to shine then it is simply a question of dividing the energy storage capacity of the battery by the rate of energy production of the solar

Storage capacity of battery $=12$ X $200 \quad \mathrm{X} \quad 3600$ Joules $=\begin{array}{llllll}8.64 & \text { MJ }\end{array}$ Time taken to charge it $=86400000 / 300=28800$ seconds or 8 hours 12 minutes

\section{Methodology}

\section{Microcontroller Memory Organization}

The microcontroller memory is divided into Program Memory and Data Memory. Program Memory $(\mathrm{ROM})$ is used for permanent saving program being executed, while Data Memory (RAM) is used for temporarily storing and keeping intermediate results and variables. Depending on the model in use (still referring to the whole 8052 microcontroller family) at most a few Kb of ROM and 128 or 256 bytes of RAM can be used. However All 8052 microcontrollers have 16-bit addressing bus and can address 64 kb memory. It is neither a mistake nor a big ambition of engineers who were working on basic core development. It is a matter of very clever memory organization which makes these controllers a real "programmers" tidbit". 


\section{Program Memory}

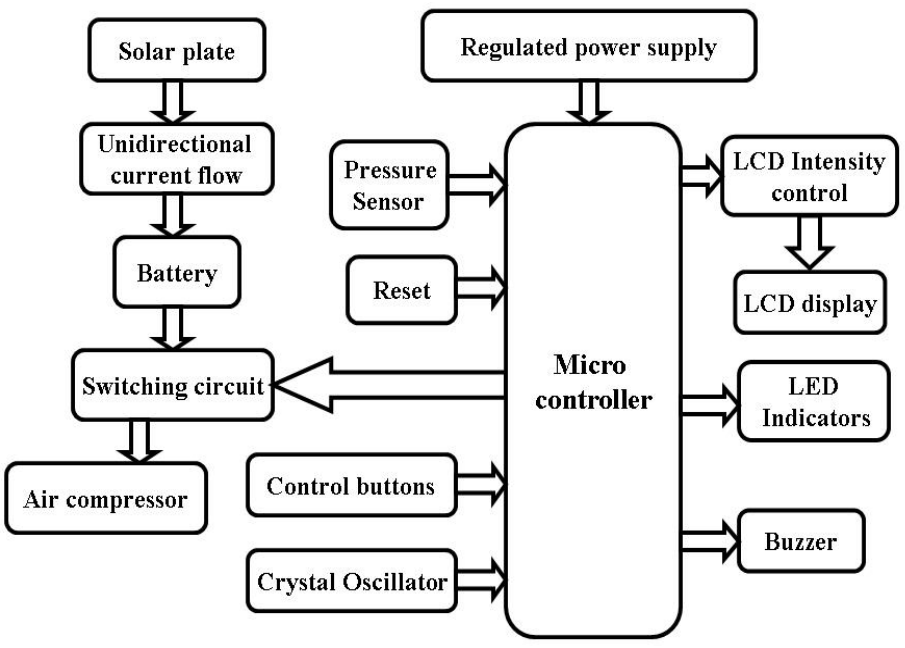

Fig 1: Solar based air compressor pump

The oldest models of the 8052 microcontroller family did not have any internal program memory. It was added from outside as a separate chip. These models are recognizable by their label beginning with 803 (for ex. 8031 or 8032) [12]. All later models have a few Kbytes ROM embedded, Even though it is enough for writing most of the programs, there are situations when additional memory is necessary. A typical example of it is the use of so called lookup tables. They are used in cases when something is too complicated or when there is no time for solving equations describing some process. The example of it can be totally exotic (an estimate of self-guided rockets' meeting point) or totally common (measuring of temperature using non-linear thermo element or asynchronous motor speed control)[7]. In those cases all needed estimates and approximates are executed in advance and the final results are put in the tables (similar to logarithmic tables).

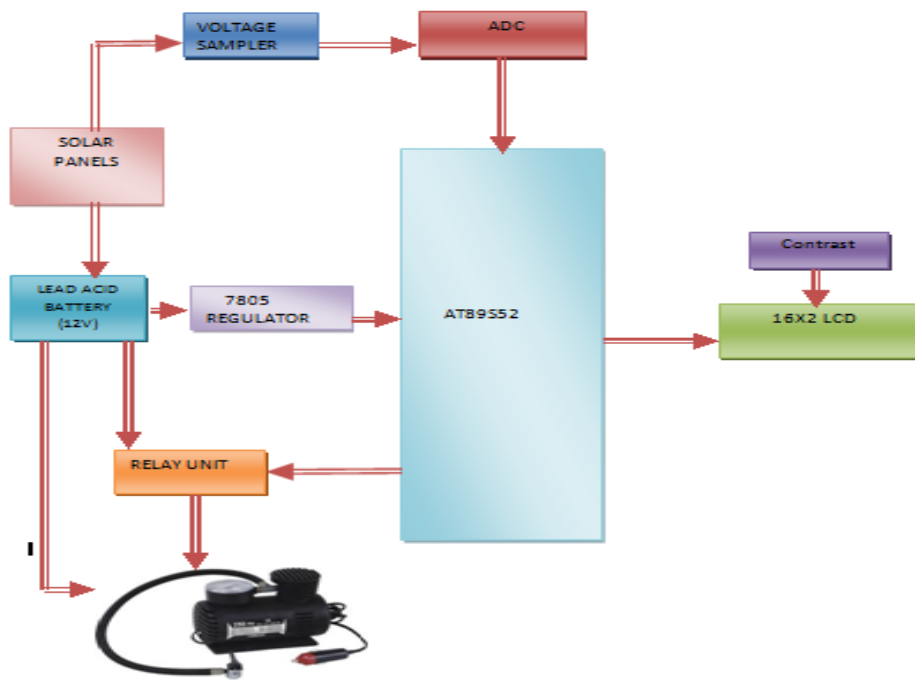

Fig 2 : Sequential steps of Microcontroller to send commands to LCD

\section{Sending Commands to LCD}

To send commands we simply need to select the command register. Everything is same as we have done in the initialization routine[6]. But we will summarize the common steps and put them in a single subroutine. Following are the steps:

- Move data to LCD port

- $\quad$ select command register

- select write operation

- send enable signal

- wait for LCD to process the command 


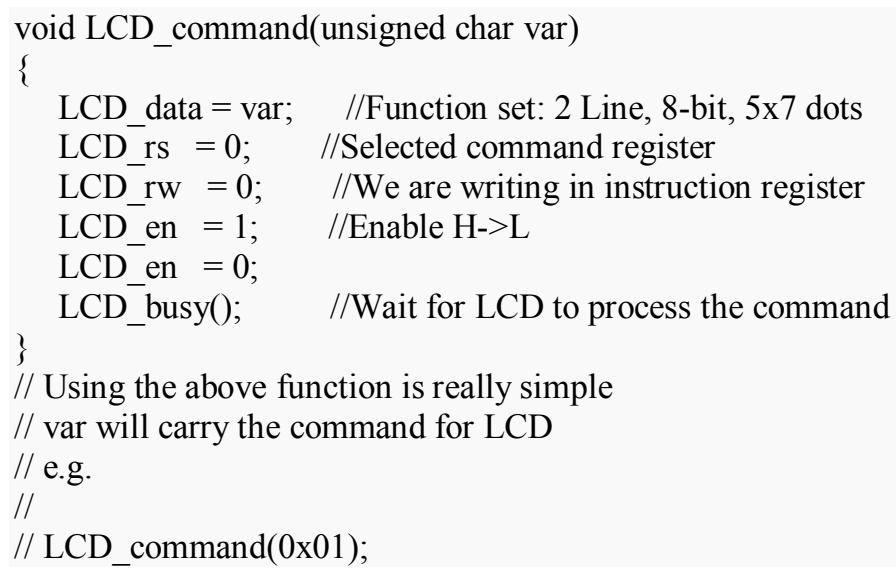

Sending Data to LCD

To send data we simply need to select the data register. Everything is same as the command routine. Following are the steps:

- Move data to LCD port

- $\quad$ select data register

- $\quad$ select write operation

- $\quad$ send enable signal

- wait for LCD to process the data

Keeping these steps in mind we can write LCD command routine as.
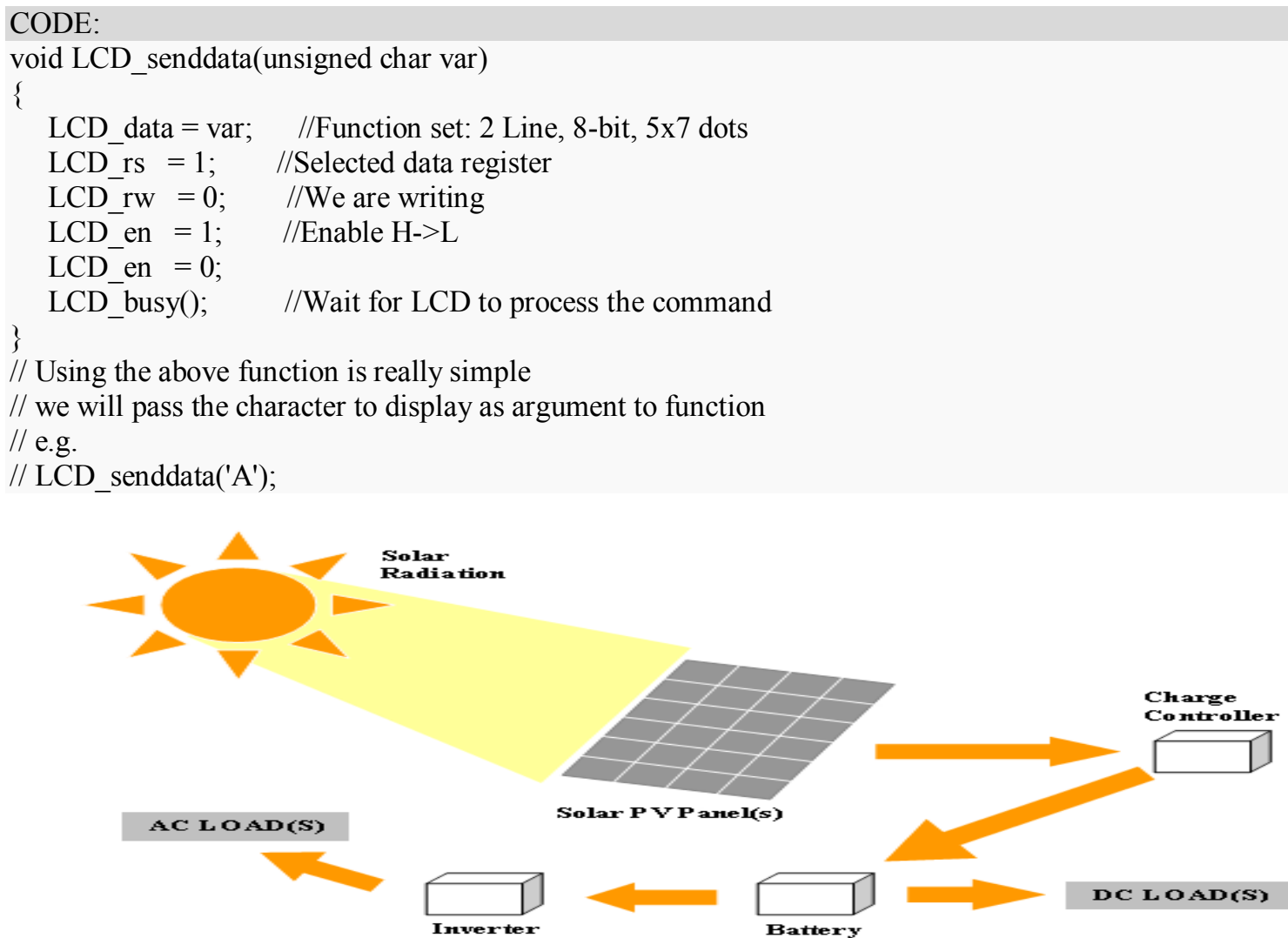

Fig 3: Schematic diagram of Solar based air compressor for inflating tyres

The radiations received from sun is collected by the solar photovoltaic cell, the energy is stored in battery bank. From battery it is sent to the air compressor if the compressor is DC motor[15]. The voltage regulator, microcontroller are used to control the fluctuation in the voltage. From batteries using inverter the energy is converted for AC motors air compressor. Once the battery is charged the energy is transfer to air compressor and starts working. 


\section{Conclusion}

The purpose for the research work had been successfully performed and it had been observed the actual operation of an Air compressor can be operated using solar panel voltage which is used to drive the air compressor effectively without any external supply that will eliminates the usage of using non conventional source of energy. This research work enables interface linking the air compressor with the help of microcontroller through relay section and also by programmatically we are calculating voltages which can be displayed on 16X2 LCD.

\section{References}

[1]. Passos, E., Meunier, F., and Gianola, J.C., 'Thermodynamic performance improvement of an intermittent solar powered refrigeration cycle using adsorption of methanol on carbon', Heat Recovery Systems, 6, 259-264, 1986.

[2]. M. Li. C. J. Sun, R. Z. Wang, W. D. Cai, “Development of No Valve Solar Ice Maker”, Applied Thermal Engineering, vol. 24, 2002, pp. 865-872.

[3]. Huang M.J., Eames P.C., Norton B., An experimental study into the application of phase change materials to limit the temperature rise in build integrated photovoltaic systems, Proceedings of Renewable Energy in Maritime Island Climates, September, Belfast, UK, 2001, 143-150.

[4]. Antonio Luque, Steven Hegedus, Handbook of Photovoltaic Science and Engineering, 2nd edition by John Wiley \& Sons, Ltd., pp. 1014-1072, 2011.

[5]. N. M. Khatlab, “A Novel Solar Adsorption RefrigerationModule”, Applied Thermal Engineering, vol. 24, 2004, pp. 2747-2760.

[6]. M. Iqbal, “An Introduction to Solar Radiation”, Academic Press, Ontario, 1983.

[7]. Dr. Ben Enis, Dr Paul Lieberman, Irving Rubin, Duane Bergmann, Randy Dirlam, Septimus van der Linden, Power Generation Sources, Transferline Compressed Air Energy Storage System with Electricity, HVAC and Desalination, Presented at PowerGen Renewable, April 10-12, 2007.

[8]. Moyer, Michael. "The New Dawn of Solar," Popular Science Best of What's New 2007.

[9]. Pollinating Bee Photo. Center for Ecology \& Hydrology, Europe, 2012.

[10]. Solar Generator Photo. Directvoltage.com. Web. 25 Nov. 2012

[11]. C. P. Arrora, Refrigeration and Air Conditioning, New Delhi, Mc Graw Hill, 2009

[12]. PIC16F877A Data Sheet, Microchip Technology Inc., 2003.

[13]. B. K. Bose, Power Electronics and AC Drives, Prentice Hall, Upper Saddle River, NJ, 2002.

[14]. Atlas Copco Airpowr NV, Compressed Air Manual, 7th ed.,Belgium, 2010

[15]. CADDET, Saving energy with efficient compressed air systems, CADDET Energy Efficiency, Max Brochure 06, 2000 